\title{
Melatonin and its therapeutic actions on peripheral nerve regeneration
}

\author{
Y. Behram Kandemir, L. Sarikcioglu \\ Department of Anatomy, Akdeniz University Faculty of Medicine, Antalya, Turkey
}

[Received 12 August 2014; Accepted 7 October 2014]

\begin{abstract}
Melatonin has many different roles in the human body, including its importance in circadian rhythms, sleep physiology, mental status, reproduction, tumour development, ageing, and many other physiologic processes. Although there are more than hundreds of studies on effects of melatonin in several tissues, its effects on peripheral nerve has been documented in a limited number of studies. This paper focused to review the available literature in terms of several actions and effects of melatonin (beneficial or toxic effects) on well-known peripheral nerve injury models. (Folia Morphol 2015; 74, 3: 283-289)
\end{abstract}

Key words: melatonin, peripheral nerve, traumatic injuries, neuroma formation

\section{MELATONIN AND ITS PHYSIOLOGIC ACTIONS}

Historical background

Melatonin (also known as N-acetyl-5-methoxytryptamine) (Fig. 1) is a hormone and is first identified in bovine pineal extracts. This hormone lightens the colour of frog melanocytes by its ability to aggregate melanin granules either after injection into the frog or after in vitro incubation with pieces of frog skin $[5,27]$. Its melanocyte-lightening property is more than ten thousand times greater than that of noradrenalin [27].

Melatonin was first defined as the hormone that mediates the annual fluctuations in reproductive competence in seasonally breeding animals, as well as influencing numerous aspects of circadian biology [39].

\section{Biosynthesis of melatonin}

Melatonin is a highly lipophilic molecule, as well as having hydrophilic properties; rather than being stored in a secretory organ, upon biosynthesis it is released into bloodstream through capillaries [29]. Tryptophan plays a key role in biosynthesis of melatonin. Tryptophan is first converted by tryptophan hydroxylase to 5-hydroxytryptophan, which is decarboxylated to serotonin. Two enzymes (serotonin $\mathrm{N}$-acetyltransferase and hydroxyindole $\mathrm{O}$-methyltransferase) that are largely confined to the pineal gland catalyse the synthesis of melatonin from serotonin [5]. As the synthesis of melatonin increases, the hormone enters the bloodstream through passive diffusion. Melatonin synthesis and release are stimulated by darkness and inhibited by light (Fig. 1). In humans, melatonin secretion increases soon after the onset of darkness, peaks in the middle of the night (between 2 and 4 a.m.), and gradually falls during the second half of the night. Serum melatonin concentrations vary considerably according to age [5].

\section{Physiologic effects of melatonin}

Both in vitro [36, 37, 40] and in vivo studies [53] have shown that the neurohormone melatonin is a more potent free radical scavenger of the highly toxic hydroxyl

Address for correspondence: Dr L. Sarikcioglu, Department of Anatomy, Akdeniz University Faculty of Medicine, 07070 Antalya, Turkey, tel: +90 242 2496952, fax: +90 242 2274485, e-mail: levent@akdeniz.edu.tr; sarikcioglul@gmail.com 


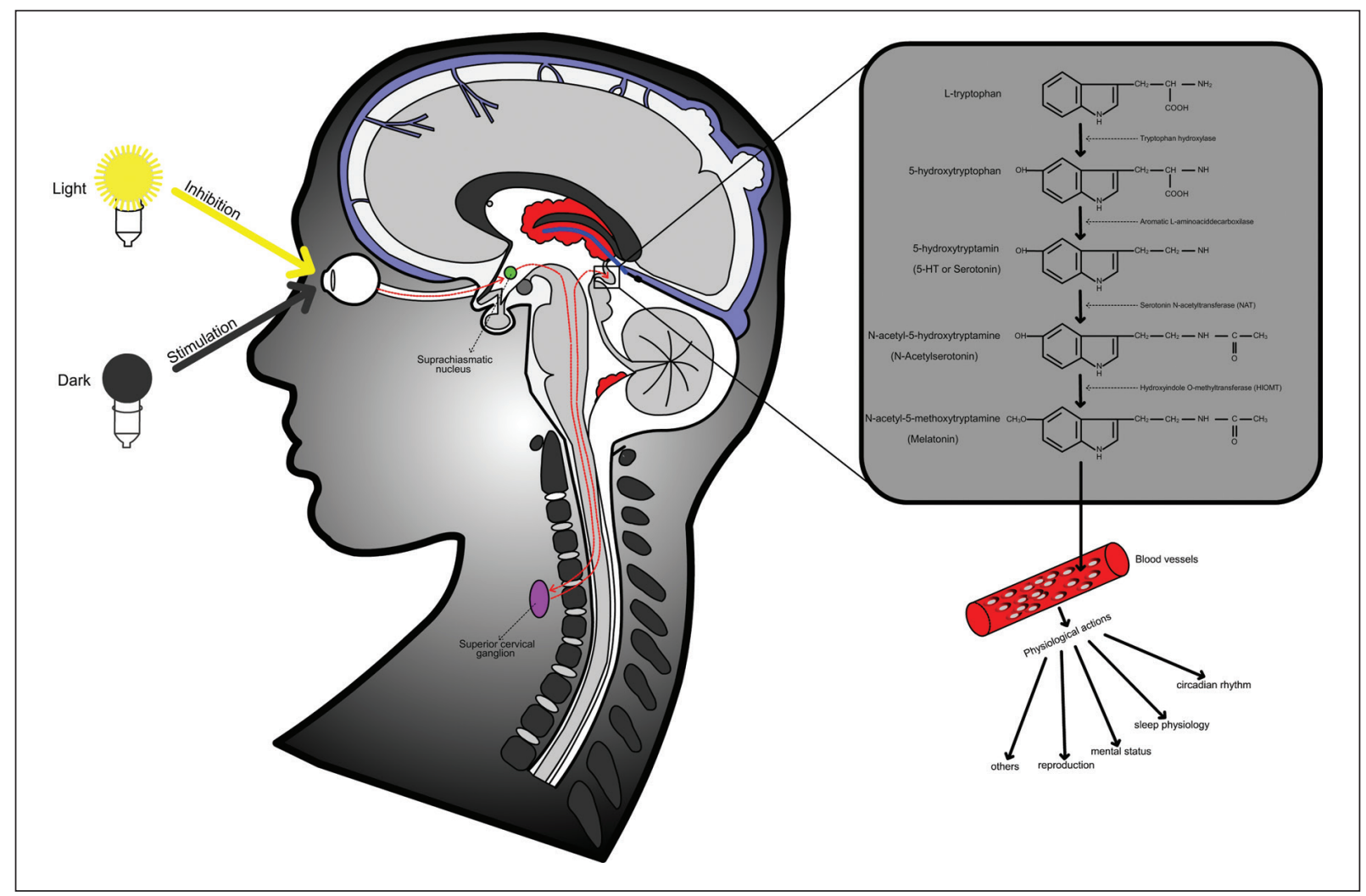

Figure 1. Biosynthesis of melatonin.

and peroxyl radicals than some other known compounds [39]. Melatonin seems to be more effective than other known antioxidants (e.g., mannitol, glutathione, and vitamin E) in protecting against oxidative damage [5]. Therefore, melatonin may provide protection against oxidative damage in some diseases that cause degenerative or proliferative changes. However, these antioxidant effects require concentrations of melatonin that are much higher than peak nighttime serum concentrations [5]. Damage of the peripheral nerve also causes the production of free oxygen radicals [2]. When damage occurs to a peripheral nerve, both ischaemic and inflammatory processes begin. As a consequence of this process, free oxygen radicals and many toxic agents accumulate around the site of injury [2].

The neurohormone melatonin is a powerful antioxidant in vivo [39]. It prevents the toxicity of singlet oxygen and stimulates the antioxidative enzyme, glutathione peroxidase [39]. Glutathione peroxidase and, as a consequence, glutathione reductase activities follow the rhythm of melatonin. Involvement of melatonin in the control of redox processes has also been addressed by its high-affinity binding to cytosolic quinone reductase 2 , previously believed to be a melatonin receptor [18].
Considering varied and potent antioxidant capability of melatonin, it has been reported that melatonin is an essential element of the antioxidant defence system of organisms [39]. Direct actions of melatonin in oxidative status may have important clinical implications considering the harmful role of free radicals in many disease processes [39].

Melatonin has many different roles in the human body, including its importance in circadian rhythms, sleep physiology, mental status, reproduction, tumour development, ageing, and many other physiologic processes [2]. Besides its well-known regulatory role on circadian rhythm, melatonin has other biological functions and a distinct metabolism in various cell types and peripheral tissues [28].

\section{MELATONIN IN TRAUMATIC INJURIES OF PERIPHERAL NERVE}

\section{Effect of melatonin treatment to reduce scar formation}

Advances in microsurgical instrumentation and great progress in nerve repair have provided the technical impetus for nerve reconstruction. However, the clinical 
results for nerve repair are usually disappointing, and functional recovery is often suboptimal after peripheral nerve injury. Scar formation is a challenge for peripheral nerve surgeon. Traditionally, surgeons attempt to control collagen scar formation by close approximation of corresponding fascicles of the proximal to distal stumps $[14,19]$. Although excellent coaptation has been achieved in matching proximal and distal nerve stumps and proper guiding axon regeneration toward the original target tissues, full recovery of nerve function does not guarantee in every patients [11].

A neuroma is a collection of disorganised nerve fibres sprouted from proximal stump of the injured nerve emanating from an interruption of axonal continuity. Excessive collagen formation can create a mechanical barrier to axonal regeneration, and the resulting scar formation can hinder axonal regrowth [21, 24, 31]. A variety of techniques have been proposed to decrease the neuroma formation characterised by accumulation of connective tissue at the lesion site $[15,19,31]$.

It has been reported that recovery of peripheral nerve depends on a balance between Schwann cell regeneration and scar tissue formation [10, 21]. Previous studies have shown that exogenous melatonin administration can reduce scar formation in nerve stump and can prevent collagen production in the granulation tissue in the peripheral nerve of the pinealectomised animals $[12,33,56]$.

Weichselbaum et al. [60] demonstrated that in pinealectomised rats, wound healing is slower than in controls, and this effect can be reversed by treatment with melatonin. Cunnane et al. [8] and Drobnik and Dabrowski. [12] reported that tissue collagen content in pinealectomised rats was found to be elevated due to low melatonin level. A variety of growth factors may play role in collagen synthesis. The immunohistochemical profile of transforming growth factor (TGF- $\beta 1$ ) and basic fibroblast growth factor (bFGF) in the lesion site of the sciatic nerve, after pinealectomy and exogenous melatonin administration, was investigated by Turgut et al. [55]. They reported that TGF- $\beta 1$ and bFGF immunoreactivity was most intense in the epineurium in animals that had undergone pinealectomy, while negative or weakly positive immunoreactivity was observed in animals in control and melatonin-treated groups [55].

\section{Proliferative effects of melatonin on Schwann cells}

A recent study demonstrated that melatonin significantly promoted Schwann cell proliferation in both in vitro and in vivo conditions following peripheral nerve injury and improved nerve regeneration [7]. The increased expression of Schwann cells induced by melatonin was clearly expressed by cell counting and the proliferative assay in spontaneous immortalised rat Schwann cell line derived from long-term culture of rat primary Schwann cells (RSC 96 cells) as well as by quantitative bromodeoxyuridine (BrdU) immunostaining and S-100 immunoexpressions in the lesioned nerves [7].

The proliferative effect of melatonin on Schwann cells has further been demonstrated to be mediated by MT1 receptor-dependent phosphorylation of extracellular signal-regulated kinases (ERK1/2) pathway $[7,28]$. Increased ERK $1 / 2$ activation would transmit signals into perikarya of the nerve for transcriptional regulation of genes related to Schwann cell differentiation and proliferation [54, 62]. It has been suggested that ERK activation is important in the establishment of a regeneration-promoting extracellular environment in proximal and distal stumps of transected nerves $[1,50]$. Seo et al. [49] also reported that increased ERK $1 / 2$ activation would contribute to Schwann cell proliferation and play an important role in sciatic nerve regeneration.

\section{Effect of melatonin on re-innervation of the motor end plates}

It is believed that the major reason for the poor functional recovery after a peripheral nerve lesion is collateral branching and regrowth of axons to incorrect muscles. It has been suggested that correct re-innervation of the neuromuscular junctions, rather than collateral axonal branching at the lesion site, may be the critical limiting factor for recovery of function after peripheral nerve injury [17]. Chang et al. [7] recently demonstrated that re-innervated motor end plates (as labelled by PGP 9.5 and a-bungarotoxin) following peripheral nerve injury was much higher in the animals receiving melatonin treatment when compared to that of saline-treated ones.

\section{Effect of melatonin treatment on apoptosis and neuronal cell death}

Melatonin is able to reduce not only apoptotic cell death in the central nervous system [38] but also the death of rat motoneurons induced by sciatic nerve transection in neonatal rats [44]. Rogerio et al. [44] reported a significant decrease in motor neuron death in the neonatal spinal cord after administration of 
melatonin at doses of $1,5,10$, and $50 \mathrm{mg} / \mathrm{kg}$ before and at 7 time intervals after sciatic nerve cut injury. In their study, neuronal survival rate was higher in those animals treated with lower doses of melatonin rather than higher doses.

\section{Therapeutic dose of melatonin}

In human studies, delivered doses of melatonin varied in a very large range, from $0.1 \mathrm{mg}$ to $2000 \mathrm{mg}$ [2]. After intravenous administration melatonin is rapidly distributed and eliminated [20], while bioavailability of orally administered melatonin varies widely [5]. Melatonin dosages over $0.5 \mathrm{mg}$ are accepted as pharmacologically therapeutic $[5,45]$.

It has been reported that plasma melatonin levels reached a steady-state after $60 \mathrm{~min}$ and $120 \mathrm{~min}$ after melatonin administration [30]. In another study, the maximal mean serum melatonin value reached $20 \mathrm{~min}$ after a single subcutaneous injection of melatonin in hamsters [57]. Moreover, peak serum melatonin levels were observed after 60-150 min and remained stable for approximately $90 \mathrm{~min}$ after administration of crystalline melatonin to 5 young male volunteers [59].

Because there is no consensus on the therapeutic dose of melatonin, different doses have been frequently used in animal studies. Shokouhi et al. [51] investigated the neuroprotective effects of melatonin on neural fibre damage and lipid peroxidation after a blunt sciatic nerve trauma, comparing the effects of low dose $(10 \mathrm{mg} / \mathrm{kg})$ and high dose $(50 \mathrm{mg} / \mathrm{kg})$ of melatonin. According to their results, low-dose melatonin $(10 \mathrm{mg} / \mathrm{kg})$ reduced trauma-induced myelin breakdown and axonal changes in the sciatic nerve. However, high-dose melatonin $(50 \mathrm{mg} / \mathrm{kg}$ ) almost entirely neutralised any ultrastructural changes. Therefore, they suggested that melatonin has a potent neuroprotective effect at a dose of $50 \mathrm{mg} / \mathrm{kg}$ and it can preserve peripheral neural fibres from lipid peroxidative damage after blunt sciatic nerve trauma [51]. Peripheral nerve functions in the ovariectomised rats receiving melatonin ( 5 or $20 \mathrm{mg} / \mathrm{kg}$ ) daily for either 2 or 6 weeks have also been examined [13].

Rogerio et al. [44] compared 1, 5, 10, and $50 \mathrm{mg} / \mathrm{kg}$ melatonin doses on motor neuron death in the neonatal spinal cord after sciatic nerve cut injury. Very low doses of melatonin have also been studied. Cunnane et al. [8] administered melatonin (30 $\mu \mathrm{g} / 100 \mathrm{~g}$ body weight) after surgical pinealectomy procedure. They found low collagen content in the lesion site, demonstrating the opposite effect of melatonin application on elevated collagen level caused by pineal gland removal [12]. Atik et al. [2] reported that beneficial effects of melatonin cannot be achieved at physiologic doses. Therefore they proposed higher doses and a longer duration of administration should be planned in experimental paradigms [2]. In line of Atik et al. [2], a potent neuroprotective effect to preserve peripheral neural fibres from lipid peroxidative damage after blunt trauma achieved by Shokouhi et al. [51] especially at a dose of $50 \mathrm{mg} / \mathrm{kg}$. In our previous studies we also administered $50 \mathrm{mg} / \mathrm{kg}$ melatonin after sciatic nerve injury $[22,23]$.

\section{Effect of disruption of melatonin treatment}

Melatonin concentrations in the body are typically lower during the day and reach to maximal levels at night in the dark [59]. In a recent study, we studied the effect of exogenous melatonin treatment on cut or crush injuries of the sciatic nerve and demonstrated that melatonin treatment had significant beneficial effect on sciatic nerve injury [22]. This treatment was performed in the light period and its effects were studied on cut and crush injury models of the sciatic nerve. In another recent study we re-addressed the beneficial effect of melatonin treatment and tried to improve this beneficial effect on cut injury by disruption of the circadian rhythm induced by light-at-night [23]. Although we used the same dose of melatonin as used in previous study [22] and found beneficial effect on sciatic nerve injury evaluated by functional, ultrastructural, biochemical tests; circadian rhythm disruption induced by light-at-night surprisingly did not demonstrate the same effect as expected [23]. We think that further studies need to be conducted to elucidate mechanism of this unexpected effect of melatonin in disrupted circadian rhythm.

\section{Combination of melatonin with other substances}

Kaplan et al. [21] studied postoperative intraperitoneal melatonin administration after intraoperative autologous platelet gel application in the collagen nerve conduit. They found that combination of melatonin with autologous platelet gel enrichment and the use of melatonin alone did not improve nerve regeneration. In the light of this negative effect, they suggested that effects of melatonin on nerve regeneration may not be because of the inhibition of collagen formation [21]. 
The effect of melatonin treatment in cut and crush injuries

The effect of the melatonin treatment has frequently been studied in neurotmesis (cut injury) model. However, in a previous study we studied its effect on axonotmesis (crush injury) and neurotmesis (cut injury) models of sciatic nerve [22]. We found that rats treated with melatonin demonstrated better structural preservation of the myelin sheaths compared to the vehicle-treated animals. The biochemical analysis also confirmed the beneficial effects of melatonin displaying lower lipid peroxidation and higher superoxide dismutase, catalase, and glutathione peroxidase activities in sciatic nerve samples in comparison to vehicle-treated animals.

\section{MELATONIN IN OTHER TYPES OF PERIPHERAL NERVE INJURIES}

Penetrating injury, crush, traction, ischaemia, and less common mechanisms such as thermal, electric shock, radiation, percussion, and vibration may be one of the aetiological factors of peripheral nerve injury [41, 42]. Ischaemia-reperfusion (I/R) is a problem that occurs in a variety of clinical conditions and leads to endoneurial oedema, segmental demyelisation, axonal degeneration, conduction failure, and multifocal or diffuse loss of nerve fibres [3, 32, 33]. Reperfusion after ischaemic insult of the tissue may elevate the production of various reactive oxygen species which damage a variety of molecules leading to cellular dysfunctions [16].

Several studies have investigated the effect of melatonin on I/R-injury. It has been well documented that melatonin provides protection against I/R injury of the liver [48], heart [25,46], intestine [9], and brain $[34,52,58]$. However, effect of melatonin on I/R injury in the peripheral nerves has only been studied by Sayan et al. [47]. They demonstrated that melatonin treatment prevented increase in the malondialdehyde levels after I/R injury of the sciatic nerve. Melatonin also restrained an I/R induced decrease in the superoxide dismutase enzyme activity. Moreover, they found that pretreatment with melatonin resulted in fewer morphologic alterations in terms of the ultrastructural features of the sciatic nerve.

\section{TOXICITY AFTER MELATONIN ADMINISTRATION}

Although there are numerous studies that mention beneficial effects of melatonin treatment on peripheral nerve pathologies, there are some experimental and clinical studies that report a toxic effect of melatonin on peripheral nerves [33]. Lehman and Johnson [26] mentioned potential drug interaction of melatonin with Zoloft (an antidepressant drug also known as Sertraline). Combined use of melatonin, Zoloft, and a high-protein diet resulted in a melatonin/ /dopamine imbalance in the retina, manifesting as a toxic optic neuropathy [26].

Melatonin is known to interact with neuronal microtubules [6] and competes with microtubule-disruptive drugs like Vinblastine and Colchicine [4, 61]. Piezzi and Cavicchia [35] studied morphological changes in microtubules of toad sciatic nerve under melatonin administration and they found that the majority of microtubules of sciatic nerve of both control and melatonin-treated groups showed disintegration after $2 \mathrm{~h}$ of cooling. Thereafter, while microtubules were reformed in the control group nerves, the disorganisation of microtubules persisted in the sciatic nerves treated with melatonin when room temperature was restored (in toad sciatic nerve, microtubules are thermodependent). Their integrity, which is disrupted by low temperature, is restored when the nerves are placed at room temperature [43].

\section{CONCLUSION AND FUTURE PERSPECTIVE}

Beneficial effects of melatonin treatment on neuroma formation at the lesion site and on recovery of function in peripheral nerve seem a particularly attractive treatment option in clinic. Although there are few studies reporting toxic effect of melatonin administration, there are great numbers of studies on beneficial effects of melatonin on peripheral nerves. We think that further studies should be carried on peripheral nerves to clearly refine beneficial or toxic effects of melatonin administration in low, therapeutic and higher doses.

Although different agents have been studied on their effect on peripheral nerve regeneration, novel drugs for peripheral nerve injury will also be required. We think that detailed studies will clarify therapeutic effects of melatonin and the use of melatonin as a neuroprotective agent could be possible in the clinical practice

\section{ACKNOWLEDGEMENTS}

The authors thank Akdeniz University Project Management Unit (Akdeniz University Research Fund) for their financial support. 


\section{REFERENCES}

1. Agthong S, Kaewsema A, Tanomsridejchai N, Chentanez V (2006) Activation of MAPK ERK in peripheral nerve after injury. BMC Neurosci, 7: 45.

2. AtikB, Erkutlu I, Tercan M, Buyukhatipoglu H, Bekerecioglu M, Pence S (2011) The effects of exogenous melatonin on peripheral nerve regeneration and collagen formation in rats. J Surg Res, 166: 330-336.

3. Bagdatoglu C, Saray A, Surucu HS, Ozturk H, Tamer L (2002) Effect of trapidil in ischemia/reperfusion injury of peripheral nerves. Neurosurgery, 51: 212-219; discussion 219-220.

4. Banerjee S, Kerrr V, Winston M, Kelleher JK, Margulis L (1972) Melatonin: inhibition of microtubule-based oral morphogenesis in Stentor coeruleus. J Protozool, 19: 108-113.

5. Brzezinski A (1997) Melatonin in humans. N Engl J Med, 336: 186-195.

6. Cardinali DP, Esquifino Al, Srinivasan V, Pandi-Perumal SR (2008) Melatonin and the immune system in aging. Neuroimmunomodulation, 15: 272-278.

7. Chang HM, Liu CH, Hsu WM, Chen LY, Wang HP, Wu TH, Chen KY, Ho WH, Liao WC (2014) Proliferative effects of melatonin on Schwann cells: implication for nerve regeneration following peripheral nerve injury. J Pineal Res, 56: 322-332.

8. Cunnane SC, Manku MS, Horrobin DF (1979) The pineal and regulation of fibrosis: pinealectomy as a model of primary biliary cirrhosis: roles of melatonin and prostaglandins in fibrosis and regulation of T lymphocytes. Med Hypotheses, 5: 403-414.

9. Cuzzocrea S, Costantino G, Mazzon E, Micali A, De Sarro A, Caputi AP (2000) Beneficial effects of melatonin in a rat model of splanchnic artery occlusion and reperfusion. J Pineal Res, 28: 52-63.

10. Davison SP, McCaffrey TV, Porter MN, Manders E (1999) Improved nerve regeneration with neutralization of transforming growth factor-beta1. Laryngoscope, 109: 631-635.

11. Deumens R, Bozkurt A, Meek MF, Marcus MA, Joosten EA, Weis J, Brook GA (2010) Repairing injured peripheral nerves: Bridging the gap. Prog Neurobiol, 92: 245-276.

12. Drobnik J, Dabrowski R (1996) Melatonin suppresses the pinealectomy-induced elevation of collagen content in a wound. Cytobios, 85: 51-58.

13. Ek RO, Zencirci SG, Dost T, Birincioglu M, Bilgin MD (2007) Effects of melatonin supplementary on the sciatic nerve conduction velocity in the ovariectomized-aged rat. Neuro Endocrinol Lett, 28: 666-670.

14. Fischer DW, Beggs JL, Kenshalo DL, Jr., Shetter AG (1985) Comparative study of microepineurial anastomoses with the use of $\mathrm{CO} 2$ laser and suture techniques in rat sciatic nerves: Part 1. Surgical technique, nerve action potentials, and morphological studies. Neurosurgery, 17: 300-308.

15. Galeano M, Manasseri B, Risitano G, Geuna S, Di Scipio F, La Rosa P, Delia G, D'Alcontres FS, Colonna MR (2009) A free vein graft cap influences neuroma formation after nerve transection. Microsurgery, 29: 568-572.

16. Grace PA (1994) Ischaemia-reperfusion injury. Br J Surg, 81: 637-647.
17. Guntinas-Lichius $O$, Irintchev $A$, Streppel $M$, Lenzen $M$, Grosheva M, Wewetzer K, Neiss WF, Angelov DN (2005) Factors limiting motor recovery after facial nerve transection in the rat: combined structural and functional analyses. Eur J Neurosci, 21: 391-402.

18. Hardeland R, Coto-Montes A, Poeggeler B (2003) Circadian rhythms, oxidative stress, and antioxidative defense mechanisms. Chronobiol Int, 20: 921-962.

19. Holmes W, Young JZ (1942) Nerve regeneration after immediate and delayed suture. J Anat, 77: 63-96.

20. Iguchi H, Kato Kl, Ibayashi H (1982) Melatonin serum levels and metabolic clearance rate in patients with liver cirrhosis. J Clin Endocrinol Metab, 54: 1025-1027.

21. Kaplan S, Piskin A, Ayyildiz M, Aktas A, Koksal B, Ulkay MB, Turkmen AP, Bakan F, Geuna S (2011) The effect of melatonin and platelet gel on sciatic nerve repair: an electrophysiological and stereological study. Microsurgery, 31: 306-313.

22. Kaya Y, Sarikcioglu L, Aslan M, Kencebay C, Demir N, Derin N, Angelov DN, Yildirim FB (2013) Comparison of the beneficial effect of melatonin on recovery after cut and crush sciatic nerve injury: a combined study using functional, electrophysiological, biochemical, and electron microscopic analyses. Childs Nerv Syst, 29: 389-401.

23. Kaya Y, Sarikcioglu L, Yildirim FB, Aslan M, Demir N (2013) Does circadian rhythm disruption induced by light-at-night has beneficial effect of melatonin on sciatic nerve injury? J Chem Neuroanat, 53: 18-24.

24. Lane JM, Bora FW, Jr., Pleasure D (1978) Neuroma scar formation in rats following peripheral nerve transection. J Bone Joint Surg Am, 60: 197-203.

25. Lee YM, Chen HR, Hsiao G, Sheu JR, Wang JJ, Yen MH (2002) Protective effects of melatonin on myocardial ischemia/reperfusion injury in vivo. J Pineal Res, 33: 72-80.

26. Lehman NL, Johnson LN (1999) Toxic optic neuropathy after concomitant use of melatonin, zoloft, and a high-protein diet. J Neuroophthalmol, 19: 232-234.

27. Lerner AB, Case JD, Mori W, Wright MR (1959) Melatonin in peripheral nerve. Nature, 183: 1821.

28. Luchetti F, Canonico B, Betti M, Arcangeletti M, Pilolli F, Piroddi M, Canesi L, Papa S, Galli F (2010) Melatonin signaling and cell protection function. FASEB J, 24: 3603-3624.

29. Macchi MM, Bruce JN (2004) Human pineal physiology and functional significance of melatonin. Front Neuroendocrinol, 25: 177-195.

30. Mallo C, Zaidan R, Galy G, Vermeulen E, Brun J, Chazot G, Claustrat B (1990) Pharmacokinetics of melatonin in man after intravenous infusion and bolus injection. Eur J Clin Pharmacol, 38: 297-301.

31. Menovsky T, Beek JF (2001) Laser, fibrin glue, or suture repair of peripheral nerves: a comparative functional, histological, and morphometric study in the rat sciatic nerve. J Neurosurg, 95: 694-699.

32. Nukada H, Powell HC, Myers RR (1993) Spatial distribution of nerve injury after occlusion of individual major vessels in rat sciatic nerves. J Neuropathol Exp Neurol, 52: 452-459.

33. Odaci E, Kaplan S (2009) Chapter 16: Melatonin and nerve regeneration. Int Rev Neurobiol, 87: 317-335.

34. Pei Z, Pang SF, Cheung RT (2002) Pretreatment with melatonin reduces volume of cerebral infarction in a rat 
middle cerebral artery occlusion stroke model. J Pineal Res, 32: 168-172.

35. Piezzi RS, Cavicchia JC (1981) Effects of cold and melatonin on the microtubules of the toad sciatic nerve. Anat Rec, 200: 115-120.

36. Poeggeler B, Saarela S, Reiter RJ, Tan DX, Chen LD, Manchester LC, Barlow-Walden LR (1994) Melatonin: a highly potent endogenous radical scavenger and electron donor: new aspects of the oxidation chemistry of this indole accessed in vitro. Ann NY Acad Sci, 738: 419-420.

37. Reiter RJ (1996) The indoleamine melatonin as a free radical scavenger, electron donor, and antioxidant. In vitro and in vivo studies. Adv Exp Med Biol, 398: 307-313.

38. Reiter RJ (1998) Oxidative damage in the central nervous system: protection by melatonin. Prog Neurobiol, 56: 359-384.

39. Reiter RJ, Oh CS, Fujimori O (1996) Melatonin Its intracellular and genomic actions. Trends Endocrinol Metab, 7: 22-27.

40. Reiter RJ, Tan DX, Poeggeler B, Menendez-Pelaez A, Chen LD, Saarela S (1994) Melatonin as a free radical scavenger: implications for aging and age-related diseases. Ann N Y Acad Sci, 719: 1-12.

41. Robinson LR (2000) Traumatic injury to peripheral nerves. Muscle Nerve, 23: 863-873.

42. Robinson LR (2004) traumatic injury to peripheral nerves. Suppl Clin Neurophysiol, 57: 173-186.

43. Rodriguez Echandia EL, Piezzi RS, Rodriguez EM (1968) Dense-core microtubules in neurons and gliocytes of the toad Bufo arenarum Hensel. Am J Anat, 122: 157-166.

44. Rogerio F, de Souza Queiroz L, Teixeira SA, Oliveira AL, de Nucci G, Langone F (2002) Neuroprotective action of melatonin on neonatal rat motoneurons after sciatic nerve transection. Brain Res, 926: 33-41.

45. Sack RL, Lewy AJ, Hughes RJ (1998) Use of melatonin for sleep and circadian rhythm disorders. Ann Med, 30: 115-121.

46. Sahna E, Acet A, Ozer MK, Olmez E (2002) Myocardial ischemia-reperfusion in rats: reduction of infarct size by either supplemental physiological or pharmacological doses of melatonin. J Pineal Res, 33: 234-238.

47. Sayan H, Ozacmak VH, Ozen OA, Coskun O, Arslan SO, Sezen SC, Aktas RG (2004) Beneficial effects of melatonin on reperfusion injury in rat sciatic nerve. J Pineal Res, 37: 143-148.

48. Sener G, Tosun O, Sehirli AO, Kacmaz A, Arbak S, Ersoy Y, Ayanoglu-Dulger $\mathrm{G}$ (2003) Melatonin and $\mathrm{N}$-acetylcysteine have beneficial effects during hepatic ischemia and reperfusion. Life Sci, 72: 2707-2718.

49. Seo TB, Oh MJ, You BG, Kwon KB, Chang IA, Yoon JH, Lee CY, Namgung U (2009) ERK1/2-mediated Schwann cell proliferation in the regenerating sciatic nerve by treadmill training. J Neurotrauma, 26: 1733-1744.
50. Sheu JY, Kulhanek DJ, Eckenstein FP (2000) Differential patterns of ERK and STAT3 phosphorylation after sciatic nerve transection in the rat. Exp Neurol, 166: 392-402.

51. Shokouhi G, Tubbs RS, Shoja MM, Hadidchi S, Ghorbanihaghjo A, Roshangar L, Farahani RM, Mesgari M, Oakes WJ (2008) Neuroprotective effects of high-dose vs low-dose melatonin after blunt sciatic nerve injury. Childs Nerv Syst, 24: 111-117.

52. Sun FY, Lin X, Mao LZ, Ge WH, Zhang LM, Huang YL, Gu J (2002) Neuroprotection by melatonin against ischemic neuronal injury associated with modulation of DNA damage and repair in the rat following a transient cerebral ischemia. J Pineal Res, 33: 48-56.

53. Tan DX, Poeggeler B, Reiter RJ, Chen LD, Chen S, Manchester LC, Barlow-Walden LR (1993) The pineal hormone melatonin inhibits DNA-adduct formation induced by the chemical carcinogen safrole in vivo. Cancer Lett, 70: 65-71.

54. Tapinos N, Rambukkana A (2005) Insights into regulation of human Schwann cell proliferation by Erk1/2 via a MEK-independent and p56Lck-dependent pathway from leprosy bacilli. Proc Natl Acad Sci USA, 102: 9188-9193.

55. Turgut M, Oktem G, Uysal A, Yurtseven ME (2006) Immunohistochemical profile of transforming growth factor-beta 1 and basic fibroblast growth factor in sciatic nerve anastomosis following pinealectomy and exogenous melatonin administration in rats. J Clin Neurosci, 13: 753-758.

56. Turgut M, Uysal A, Pehlivan M, Oktem G, Yurtseven ME (2005) Assessment of effects of pinealectomy and exogenous melatonin administration on rat sciatic nerve suture repair: an electrophysiological, electron microscopic, and immunohistochemical study. Acta Neurochir, 147: 67-77; discussion 77.

57. Vaughan GM, Mason AD, Jr., Reiter RJ (1986) Serum melatonin after a single aqueous subcutaneous injection in Syrian hamsters. Neuroendocrinology, 42: 124-127.

58. Wakatsuki A, Okatani Y, Shinohara K, Ikenoue N, Fukaya T (2001) Melatonin protects against ischemia/reperfusion-induced oxidative damage to mitochondria in fetal rat brain. J Pineal Res, 31: 167-172.

59. Waldhauser F, Waldhauser M, Lieberman HR, Deng MH, Lynch HJ, Wurtman RJ (1984) Bioavailability of oral melatonin in humans. Neuroendocrinology, 39: 307-313.

60. Weichselbaum R, Patel M, Das Gupta TK (1975) Influence of the pineal on wound healing. Nature, 254: 349.

61. Winston M, Johnson E, Kelleher JK, Banerjee S, Margulis $L$ (1974) Melatonin: cellular effects on live stentors correlated with the inhibition of colchicine-binding to microtubule protein. Cytobios, 9: 237-243.

62. Zhang W, Liu HT (2002) MAPK signal pathways in the regulation of cell proliferation in mammalian cells. Cell Res, 12: 9-18. 